\section{Automatisierte quantitative Image-Zytometrie bronchialer Spülflüssigkeiten bei Verdacht auf broncho-pulmonale Tumoren: Vergleich mit Zytologie, Histologie und klinischer Diagnose}

Zusammenfassung: Die automatisierte Image-Zytometrie wurde in den letzten Jahren zu einem sensitiven Verfahren zur quantitativen Analyse der Kernstruktur und des DNA-Gehaltes exfoliierter Zellen des Atemtraktes entwickelt. In der vorliegenden Untersuchung wollten wir die Frage klären, ob bei der Diagnose broncho-pulmonaler Tumoren bereits eine enge Übereinstimmung zwischen den Ergebnissen der automatisierten Image-Zytometrie mit den zyto- und histo-pathologischen Befunden, sowie der abschließenden Enddiagnose als „Goldstandard“ besteht. An 142 konsekutiv untersuchten Patienten (100 Männer, 42 Frauen) mit Verdacht auf einen broncho-pulmonalen Tumor wurde im Rahmen der Bronchoskopie eine Spülung des suspekten Bronchialabschnittes zusätzlich zur Gewinnung des zyto- und/oder histologischen Probenmaterials durchgeführt. Es folgte eine zytometrische Untersuchung der Spülflüssigkeit mit einem automatisierten Image-Zytometer unter Verwendung eines neu entwickelten Classifiers für die Zellen des Atemtraktes. Als Kontrollen dienten Spülflüssigkeiten von 50 Patienten ohne konkreten Tumorverdacht, bei denen eine Bronchoskopie aufgrund anderer Indikationen stattfand. Bei 108 Patienten wurde der Verdacht eines broncho-pulmonalen Tumors in der Enddiagnose bestätigt. In 97 Proben fand sich eine vermehrte Anzahl auffälliger Zellkerne. Weitere 36 waren unauffällig und in 9 Proben befand sich zu wenig repräsentatives Material. Die Spülflüssigkeiten der Kontrollprobanden waren sämtlich unauffällig. Der Vergleich mit der abschließenden Diagnose als Synthese aus allen Diagnoseverfahren zeigte für die Untersuchung bronchialer Spülflüssigkeiten mittels Image-Zytometrie eine Sensitivität von $90 \%$ (92/102) bei einer Spezifität von $84 \%$ (26/31). Histopathologie: $91 \%$ Sensitivität $(73 / 80)$ bei $100 \%$ Spezifität (6/6). Zytologie $92 \%$ Sensitivität $(92 / 100)$ und $100 \%$ Spezifität (26/26). Für die automatisierte Zytometrie ergab sich damit ein positiver Vorhersagewert von $95 \%$ und ein negativer Vorhersagewert von $71 \%$. Die quantitative Image-Zytometrie bronchialer Spülflüssigkeiten erwies sich damit als empfindliche und zuverlässige Methode zur Erfassung und Charakterisierung zellulärer Atypien bei bronchopulmonalen Tumoren. Automatisiert und nahezu bedienungsfrei arbeitend, bietet sie sich als ein effektives Verfahren für die erste Stufe im Rahmen des Lungenkrebs-Screenings an.

Automated Quantitative Image Cytometry of Bronchial Washings in Suspected Lung Cancer Compared to Cytology, Histology and Final Diagnosis: Introduction: Automated image cytometry represents a new method for the quanti-

Pneumologie 53 (1999) 583-595

(c) Georg Thieme Verlag Stuttgart · New York
W. Marek' ${ }^{1}$, S. Krampe ${ }^{1}$, N. J. Dickgreber ${ }^{1}$, L. Nielsen ${ }^{1}$, A. Muti' ${ }^{1}$, B. Khanavkar ${ }^{1}$, K. M. Müller ${ }^{2}$, Z. Atay ${ }^{3}$, Th. Topalidis ${ }^{3}$, J. A. Nakhosteen ${ }^{1}$

${ }^{1}$ Forschungsinstitut für Frühdiagnose und Therapie des Bronchialkarzinoms, Klinik für Pneumologie und respiratorische Allergologie, Augusta-Kranken-Anstalt, Bergstr. 26, 44790 Bochum

${ }^{2}$ Institut für Pathologie, Berufsgenossenschaftliche Kliniken Bergmannsheil, Ruhr-Universität-Bochum

${ }^{3}$ Zytologisches Institut Atay und Topalidis, Hannover

tative analysis of nuclear structure and DNA-content of exfoliative airway epithelial cells. In the present investigation, we examined the correlation between automated cytometry, conventional cytology and histopathology with the final diagnosis as the "gold standard". Methods: In 142 patients (100 males and 42 females) with suspected lung cancer and 50 controls (COPD, asthma), bronchial washings $(5-10 \mathrm{ml})$ were obtained during bronchoscopy before taking biopsies for cytological and/or histological examinations. The washings were collected in $20 \mathrm{ml}$ Saccomanno's fixative and centrifuged ( $500 \mathrm{~g}, 15 \mathrm{~min}$ ). The cell pellet was resuspended in Saccomanno's solution. Two specimens were stained according to Papanicolaou and another two using the Feulgen reaction with thionin. Image cytometry was performed by means of a special, trainable classifier for exfoliative cells of the respiratory tract, using the Cyto-Sacant ${ }^{\circledR}$ (Oncometrics, Vancouver). Results: In the patients with suspected lung cancer we found numerous abnormal nuclei in 97 samples. 36 samples contained normal cells only, and 9 samples were insufficient. In our control group there was no sample with abnormal nuclei, and all washings were evaluable. Compared to the final diagnosis of lung cancer, we found a sensitivity of $90 \%(92 / 102)$ and a specificity of $84 \%(26 / 31)$. For histology sensitivity was $91 \%(73 / 80)$ and specificity $100 \%$, while we found a sensitivity of $92 \%(92 / 100)$ and specificity of $100 \%$ for cytology. For automated cytometry the positive predicted value was $95 \%$, the negative predicted value $71 \%$. Conclusions: In the investigation of patients with suspected lung canver, automated image cytometry of bronchial washings is a sensitive and reliable method for the detection of malignant changes in the tracheobronchial mucosa. The automated procedure seems well suited not only for analysing bronchial washings, but also for a screening procedure.

\section{Einleitung}

Um das Ziel, ein wirksames Screeningprogramm für den Lungenkrebs zu realisieren, mußte zunächst die automatisierte Zytometrie von Zellen bösartiger Lungentumoren ermöglicht werden. Die Automatisierung der Zytometrie wurde in jüngster Zeit durch leistungsfähige Computer-Hard- und Software in Kombination mit hochauflösenden Videosystemen auf Feinrobotik ermöglicht $[4,14,20,29]$.

Eine Anlage, die in der Lage ist, eine quantitative Analyse der Kernstruktur und des Chromatin-Gehaltes automatisiert durchzuführen, wurde im Januar 1996 in unserer ZytometrieEinheit etabliert und für den klinischen Einsatz weiterentwikkelt $[19,26]$. Diese Arbeit sollte vorbereitend für nachfolgende 
Sputumuntersuchungen zunächst prüfen, inwieweit die zytometrischen Untersuchungsergebnisse der in der Regel materialreichen und unter optischer Kontrolle gewonnenen bronchialen Spülflüssigkeiten mit zytologischen und histologischen Ergebnissen sowie der Enddiagnose übereinstimmen.

Die automatisierte Image-Zytometrie wurde in den letzten Jahren als ein sensitives Verfahren zur quantitativen Analyse von Kernstrukturen und des DNA-Gehaltes exfoliierter Zellen entwickelt. Sie fand ihren Einsatz zunächst in der Untersuchung von Zervixabstrichen [3,7-9]. Nun bietet sich mit der Weiterentwicklung und Automatisierung ein neuer Einsatzbereich an: die Untersuchung epithelialer und makrophagozytärer Zellen des Atemtraktes aus bronchialen Spülflüssigkeiten oder Sputa [11,14].

Angesichts einer - allen Therapien zum Trotz - unverändert schlechten Prognose des Lungenkrebses zeigt sich dennoch, daß die Frühdiagnose des Lungenkrebses die Sterberate deutlich senken kann [5]. Auch heute noch stirbt, trotz der seit den 60er Jahren rückläufiger Krebsmortalität, knapp jeder vierte Bundesbürger infolge eines Krebsleidens. Dabei steht der Lungenkrebs nach Angaben der WHO mit 26,7\% aller malignen Neoplasien bei den Männern und 6,7\% bei den Frauen an der Spitze der Krebstodesursachen der Männer und bei den Frauen an 4. Stelle hinter dem Brust-, Dick- und Enddarmkrebs [12]. In den USA stellen Lungentumoren sogar $34 \%$ aller Krebstodesfälle von Männern und 22\% der Krebstodesfälle von Frauen. Die dem Lungenkrebs zuzuschreibenden Todesraten, stiegen im Verlauf dieses Jahrhunderts drastisch an. Seit den 60er Jahren verzeichnete das Statistische Bundesamt in der Bundesrepublik bei den Männern einen stetigen Aufwärtstrend der Lungenkrebs-Sterbeziffer von 55 auf 70 pro 100000 Einwohner. In den 80er Jahren kam es zu einem Stillstand dieser Entwicklung und seit Anfang der 90er Jahre wird ein rückläufiger Trend beobachtet, wobei letzteres für die neuen Bundesländer nicht uneingeschränkt gilt. Bei den Frauen zeigt sich eine andere Entwicklung. Es findet sich weiterhin ein stetiger Aufwärtstrend, wobei die Sterbeziffer sich seit den 60er Jahren fast verdoppelt hat. Im Vergleich zu den Männern ist sie mit 20 pro 100000 Einwohner z.Z. jedoch noch relativ niedrig (Statistisches Bundesamt). Insgesamt starben allein in unserem Land 36748 Menschen im Jahr 1996 an bösartigen Neubildungen der Lunge und Bronchien.

In den Jahren von 1960 bis 1980 stieg die Mortalität an Lungenkrebs nach Angaben der WHO in den industrialisierten Ländern um $76 \%$ bei den Männern und bei den Frauen sogar um $135 \%$ an.

Nach Angaben der American Cancer Society wurden 1995 in den USA 169900 Lungentumoren diagnostiziert und 157400 Todesfälle erwartet [1]. Die 5-Jahres-Überlebensraten für den Lungenkrebs sind, verglichen mit anderen Tumoren, klein und haben sich in den letzten 25 Jahren kaum verbessert [5]. Unter den in den Jahren 1981-1987 neu diagnostizierten Fällen beträgt die 5-Jahres-Überlebensrate lediglich 11,8\% für Männer und 16,3\% für Frauen. Die 5-Jahres-Überlebensrate für Tumoren, die in frühen, lokal begrenzten Stadien entdeckt wurden, ist mit $47 \%$ signifikant höher [5]. Jedoch werden nur $18 \%$ der Tumoren in einem früheren Stadium entdeckt. Nichtkleinzellige bösartige Lungentumoren könnten grundsätzlich früher entdeckt und entsprechend behandelt werden. Die 5-
Jahres-Überlebensraten hängen deutlich vom Diagnosezeitpunkt ab. Für das Stadium I wird eine Rate von $76 \%$, für Stadium II eine von $25 \%$, weniger als $7 \%$ für die Stadien IIIA und IIIB, ein Tumor im Stadium IV wird nur in Ausnahmefällen fünf Jahre überlebt [16].

Diese Tatbestände unterstreichen die Notwendigkeit der Früherkennung bösartiger Lungentumoren. Für eine wirkungsvolle Frühdiagnostik werden dringend neue Methoden benötigt [24]. Eine Möglichkeit könnte die hier vorgestellte automatisierte Image-Zytometrie in ihrer Weiterentwicklung für das Sputum-Screening sein $[11,14,18,29]$. Sie stellt ein sensitives Verfahren zur quantitativen Analyse der Kernstruktur und des DNA-Gehaltes exfoliativer Zellen, wie die des Atemtraktes dar. Gegenüber der herkömmlichen Durchflußzytometrie werden nicht nur die Kerngröße und der DNAGehalt der zu untersuchenden Kerne bestimmt, sondern die Kernstruktur wird - vergleichbar der zytologischen Untersuchung - anhand einer Vielzahl unterschiedlicher Chromatinstrukturen (Features) analysiert und quantifiziert. Die weitgehende Automatisierung des Verfahrens ermöglicht eine arbeitszeitunabhängige Bearbeitung der Präparate auch in Abwesenheit des Untersuchers. Sie bietet die Möglichkeit, eine größere Anzahl von Proben ohne wesentlichen personellen Mehraufwand zu untersuchen. Sie eignet sich als diagnostisches Verfahren und damit auch für umfangreiche Screeninguntersuchungen.

In der vorliegenden Studie wollten wir die Frage klären, ob der gegenwärtige Stand der automatisierten Image-Zytometrie bei ihrem Einsatz in der Untersuchung bronchialer Spülflüssigkeiten bereits eine zuverlässige Übereinstimmung mit den Ergebnissen von zyto- und histo-pathologischen Untersuchungen von Biopsie-Präparaten zeigt.

Unter Verwendung eines automatisierten Image-Zytometers (Cyto-Savant ${ }^{\circledR}$ ) untersuchten wir bronchiale Spülflüssigkeiten von 142 konsekutiv untersuchten Patienten, die wegen des Verdachts auf einen broncho-pulmonalen Tumor in der pneumologischen Klinik der Augusta-Kranken-Anstalten bronchoskopiert wurden. Als Kontrollkollektiv dienten 50 Patienten ohne neoplastische Veränderungen, bei denen eine Bronchoskopie aus anderen Gründen erfolgte.

Unsere Ergebnisse belegen, daß die quantitative Image-Zytometrie bei der Untersuchung bronchialer Spülungen zu einem standardisierten und zuverlässigen Verfahren mit hoher Sensitivität und Spezifität weiterentwickelt werden kann, das zudem weitgehend automatisiert und bedienungsfrei arbeitet.

\section{Methodik}

\section{Patienten}

An 142 Patienten mit dem Verdacht auf einen bronchopulmonalen Tumor führten wir eine Spülung des suspekten Bronchialabschnittes zusätzlich zur Gewinnung des zytologischen und/oder histologischen Probenmaterials im Rahmen einer Bronchoskopie durch. Untersucht wurden im Zeitraum von Mai 1996 bis April 1997 insgesamt 42 Frauen und 100 Männer im Alter zwischen 26 und 85 Jahren, Median 65 Jahre. Bei allen Patienten dieser Gruppe bestand der klinische und/ oder röntgenologische Verdacht auf einen broncho-pulmona- 
len Tumor, oder ein solcher sollte durch die bronchoskopische Untersuchung ausgeschlossen werden. Bei sämtlichen Patienten wurde vor der Bronchoskopie eine Röntgenuntersuchung des Thorax vorgenommen. Im Rahmen der weiterführenden Diagnostik erfolgte eine flexible Bronchoskopie. Für 86 Patienten (60\%) lagen Angaben zum Rauchverhalten komplett vor, darunter fanden wir in 95\% der Fälle Raucher mit durchschnittlich 47 Pack-Years. Unter den Tumorpatienten mit bekanntem Rauchverhalten fanden wir in $97 \%$ der Fälle Raucher und nur in 3\% Nichtraucher. In 9 der 142 untersuchten bronchialen Spülflüssigkeiten befand sich zu wenig repräsentatives Material, so daß schließlich 133 Patienten in die Vergleichsuntersuchung aufgenommen werden konnten.

\section{Kontrollkollektiv}

Als Kontrollen dienten bronchiale Spülflüssigkeiten von 50 Patienten (30 Männer, 20 Frauen) bei denen eine Bronchoskopie aufgrund anderer Indikationen, (Sarkoidose, therapeutische Lavage bei COPD oder Asthma) durchgeführt wurde. Darunter waren 22 Nichtraucher und 28 Raucher bzw. Exraucher mit mehr als 20 Packungsjahren.

\section{Bronchoskopie}

Wegen des Verdachtes auf das Vorliegen eines bronchopulmonalen Tumors führten wir im Rahmen des diagnostischen Vorgehens eine konventionelle Bronchoskopie durch. Indikation zur Bronchoskopie war ein klinischer oder radiologischer Verdacht auf einen broncho-pulmonalen Tumor. Die Untersuchung erfolgte in Lokalanästhesie und, falls erforderlich, unter Zuhilfenahme einer i.v. Sedierung. Wir verwendeten flexible Bronchoskope vom Typ Olympus BFP 30, BF 20 und BF 200.

Die bronchoskopischen Befunde teilten wir in drei Gruppen ein:

1. unauffällige oder entzündliche Veränderungen der bronchialen Schleimhaut,

2. direkte Tumorzeichen (in das Bronchiallumen wachsende stenosierende Tumoren mit der Möglichkeit zur Exfoliation von Tumorzellen),

3. indirekte Tumorzeichen (submuköse Infiltration im Sinne einer Verbreiterung der Lappen- bzw. Segmentkarinen oder Subsegmentkarinen mit Kompression bzw. Bronchialstenose, einschließlich Verstreichungen der Schleimhaut oder der Knorpelstruktur assoziiert mit lokalen Hypervaskularisationen).

\section{Bronchiale Spülungen/Materialgewinnung}

In den suspekten Bronchialabschnitten wurden vor den üblichen Probeexzisionen Spülungen mit $2 \times 8 \mathrm{ml}$ isotoner Kochsalzlösung über den Arbeitskanal durchgeführt. Das Aspirat (ca. $10 \mathrm{ml}$ ) wurde in $20 \mathrm{ml}$ Saccomanno-Konservierungslösung aufgenommen. Noch am gleichen Tag erfolgte die Aufbereitung des Probengutes. Bei Patienten ohne radiologischen oder bronchoskopischen Lokalbefund sowie bei den Kontrollprobanden spülten wir die zentralen Bronchialabschnitte.

\section{Färbeverfahren}

Nach Zentrifugation über 15 Minuten bei $500 \mathrm{~g}$ wurde das Zellpellet in 0,5-1,5 ml Saccomanno-Lösung [31] mittels Pasteurpipette resuspensiert. Der Überstand wurde verworfen. Jeweils zwei Tropfen der Zellsuspension (ca. 0,2 ml) gaben wir auf sechs Objektträger und strichen die Proben mit einem zweiten Objektträger analog einer Blutprobe aus. Anschließend erfolgte die Trocknung an der Luft mindestens über einen Zeitraum von 12 Stunden.

Jeweils zwei Präparate färbten wir für die zytologische Untersuchung nach Papanicolaou [27] und zwei nach saurer Hydrolyse mit Thionin [13, 17, $33-35]$.

\section{Zytologie}

Die lichtmikroskopischen zytologischen Untersuchungen von Tupfpräparaten bzw. der Abstriche oder Zytozentrifugate erfolgten unabhängig voneinander im Zytologischen Institut Atay und Topalidis und/oder im Forschungsinstitut für Frühdiagnose und Therapie des Bronchialkarzinoms. Die Befundung der zytologischen Präparate wurde nach einer modifizierten Papanicolaou-Klassifikation durchgeführt [2, 28], darin bedeuten PAP-Klasse 0 nicht repräsentatives Material, PAPKlasse I ein normales Zellbild, PAP-Klasse II gutartige Erkrankungen, PAP-Klasse III Zellproliferationen mit Zellatypien oder -anomalien (unklare Befunde), PAP-Klasse III $_{D}$ Dysplasien (leicht, mäßig, schwer), PAP-Klasse IV $_{\mathrm{a}}$ Carcinoma in situ, PAPKlasse $\mathrm{IV}_{\mathrm{b}}$ einzelne sichere Tumorzellen (Karzinom sehr wahrscheinlich), PAP-Klasse V mehrere/viele Tumorzellen (sicheres Karzinom). Zusätzlich zur Klassifikation erfolgte die Diagnose mit einem Freitext. In die Auswertung floß jeweils die Diagnose mit dem höchsten Grad der neoplastischen Veränderung ein.

Wenn notwendig erfolgten zusätzlich zu den Färbungen nach Papanicolaou und May-Grünwald-Giemsa, zytochemische Färbungen (unspezifische Esterase, alkalische und saure Phosphatase, PAS, Amylase-PAS, ) sowie immunzytochemische Färbungen (CEA, NSE, Vimentin) zur weiterführenden Spezifikation des Tumortyps bzw. der Diagnose.

\section{Automatisierte Image-Zytometrie}

Die zytometrische Untersuchung des Probenmaterials erfolgte mit dem Cyto-Savant ${ }^{\circledR}$ (Oncometrics Imaging Corp. Vancouver, CDN) unter Verwendung eines speziell entwickelten trainierbaren automatisierten Classifiers (TANC, Trainable Automated Nuclear Classifier) für exfoliative Zellen des Atemtraktes, mit dem auch Untersuchungen von Sputumproben bereits routinemäßig durchgeführt werden.

Für die zytometrischen Untersuchungen wurden die Präparate unter Verwendung von Thioninsulfid nach saurer Hydrolyse gefärbt $[13,34,35]$. Die Präparate wurden zuerst $30 \mathrm{~min}$ in 96\%igem Ethanol dehydriert, anschließend 30-60 min in Böhm-Sprenger-Lösung fixiert und dann mit Aqua dest. gespült. Die Purinbasen wurden bei Zimmertemperatur $\left(20^{\circ} \mathrm{C}\right)$ durch eine 45 minütige Hydrolyse in $5 \mathrm{~N} \mathrm{HCl}$ entfernt. An die Aldehydgruppen band sich das Thionin- $\mathrm{SO}_{2} \mathrm{im}$ anschließenden Färbeschritt (60 min) streng stöchiometrisch und wurde photometrisch im blau-violetten Bereich bei $590 \mathrm{~nm}$ bestimmt. Anschließend wurden die Präparate mehr- 
fach in einer Natriumbisulfit-Lösung zur Entfernung von Farbresten gespült. Abschließend erfolgte die Spülung in Ethanollösungen zunehmender Konzentrationen und schließlich in Xylol, bevor die Proben in Immersionsöl eingebettet wurden.

Die Analysezeit des automatisierten Zytometers betrug eine halbe Stunde, während dieser Zeit wurden bis zu 1500 Zellkerne rekrutiert und ihre Kernstrukturen quantitativ bestimmt. Als Referenzzellen für die Normalisierung der Zellkernstrukturen dienten jeweils 25 in der jeweiligen Probe gefundene Lymphozyten. Die Unter- und Obergrenze der zu analysierenden Anzahl der Kerne war für jede Gruppe frei wählbar.

Bei einer 20fachen Vergrößerung und einer Bildmatrix von $1,4^{*} 10^{6}$ Pixeln der verwendeten CCD-Videokamera (Kodak Microimager 1400) und einer Bildschirmauflösung von $1246 \times 1026$ Bildpunkten betrug die Kantenlänge eines Pixels ca. 0,33 $\mu \mathrm{m}$. Die Anzahl der Pixel ergab die Kerngröße, ein typischer Epithelzellkern mit 10-12 $\mu$ m Durchmesser umfaßte ca. 1000 Pixel. Die Farbintensität aller einzelnen Pixel wurde bei einer Wellenlänge von $590 \mathrm{~nm}$ photometrisch gemessen. Der Graubereich von weiß bis schwarz umfaßte 256 Stufen, die Summe aller Graustufen der Pixel eines Kerns wird als integrierte optische Dichte (IOD) bezeichnet und entspricht dem DNA-Gehalt des Kerns. Der Standardwert für die IOD epithelialer Kerne betrug 110, zugelassen war ein Bereich von $\pm 50 \%$ des Standards. Die IOD der normalen Epithelzellkerne wurde gleich 1,0 gesetzt und als DNA-Index bezeichnet. Ein DNA-Index von 1,0 entspricht dem doppelten haploiden DNA-Gehalt (2c) eines normalen Kernes in der Ruhephase. Die Obergrenze für die Größe der zu sammelnden Objekte betrug 350000 Rähmchen (zentrales Pixel mit einer Pixelumrandung), die Untergrenze 1500.

Das Gerät ermöglicht die quantitative Untersuchung von mehr als 100 verschiedenen Kernstruktureigenschaften, die dem automatisierten Zell-Classifier bei der Einteilung der untersuchten Objekte in die einzelnen Zellkerngruppen und der Zellsammlung zugrunde liegen [11]. An den einzelnen Knotenpunkten des Sortierbaums werden Schwellenwerte einzelner Kernstrukturparameter definiert und linear-diskriminierende Funktionen aus den Kernstruktureigenschaften berechnet, die eine größtmögliche Trennung der gewünschten Zellgruppen ermöglichen. Zur Ersparnis von Rechnerzeit für die Zellsammlung und Analyse wurden Schwellenwerte festgelegt, die nur die Sammlung von Objekten zulassen, die im voreingestellten Bereich liegen. Primär werden darin die Größe und die optische Dichte der Objekte festgelegt. Zur Analyse des Bronchialsekretes wurden maximal 500 normale Epithelzellkerne und zwei Gruppen mit bis zu 200 auffälligen Kernen im Bereich 1,25<DNA-Index <2,5 und bis zu 100 Kernen mit einem DNA-Index $>2,5$ gesammelt. Hinzu kamen bis zu 100 Kondensatalveolarmakrophagen [23] und jeweils bis zu 200 Lymphozyten, segmentkernige und eosinophile Granulozyten. Die maximale Sammeldauer wurde auf $30 \mathrm{~min}$ festgelegt. Die Analyse wurde abgebrochen, wenn die Mindestanzahl der gesuchten Zellen in dieser Zeit nicht erreicht wurde. Für jede der etwa 1500 Zellen wurden die Meßwerte aller Kernstruktureigenschaften berechnet und gespeichert. Die Lokalisation ( $\mathrm{x}$ - und $\mathrm{y}$-Koordinaten) sämtlicher Zellen wurde bestimmt. Auffällige Kerne konnten daher einzeln mikroskopisch überprüft werden.
Vor der Analyse eines Satzes von bis zu 50 Proben, die das Gerät ohne Anwesenheit des Untersuchers bearbeitet, wurde eine Eichung des Zytometers und eine Kontrolle der Optik durchgeführt (Zeitaufwand ca. 5 Minuten). In seiner gegenwärtigen Version können bei einer Analysezeit von 30 Minuten mindestens 48 Präparate pro Tag untersucht werden. Die Revision durch den Untersucher, einschließlich Erstellung und Ausdruck des Befundes, benötigt in der Regel fünf bis zehn Minuten. Während der 30minütigen Zellsammlung werden in der aktuellen Softwareversion bis zu 50000 Objekte erfaßt, davon wird in einem „sauberen“ Präparat etwa ein Drittel als Kerne der unterschiedlichen Kategorien identifiziert. Eine wöchentliche Datensicherung mittels Streamer (HP 35480A) wird parallel zur Datenaufnahme bzw. -revision durchgeführt. Eine aktuelle Übersicht über die Einsatzmöglichkeiten und Kosten der statischen Bildzytometrie in der Diagnose epithelialer Dysplasien findet sich bei Böcking [6].

\section{Zytometrische Befundung}

Den DNA-Gehalt epithelialer diploider Zellen (2c-Wert oder Euploidiewert) erhält man z.B., indem man die IOD einer Anzahl von Lymphozyten bestimmt und mit einem laboreigenen Faktor multipliziert. So schlagen z.B. Böcking et al. [9] einen Faktor von 1,2 vor, wenn in 50\% alkoholfixierte Präparate eine Stunde mit 4N HCl hydrolysiert worden sind.

Der DNA-Bereich euploider Zellkerne beträgt $2 c \pm 0,25$ c und entspricht damit etwa einem Varianzkoeffizienten von 12,5\%. Als quantitative Meßgrößen wurden aus den Einzelwerten des DNA-Gehaltes folgende Parameter bestimmt: die Raten der 2,5c und $5 c$ - überschreitenden Zellen (2,5cER und 5cER) und der 2c-Abweichungs-Index (2cDI) [9].

Von Böcking [7] sowie der ESACP [9] wurden Kriterien für die quantitative Analyse der Imagezytometrie aufgestellt, die als Grundlage für unsere Beurteilung dienten. Der 5cER ist der prozentuale Anteil der aneuploiden Zellen, deren DNA-Gehalt größer als $5 c$ ist. Es handelt sich hierbei um nicht in Teilung befindliche Kerne. Zellen wurden als aneuploid bezeichnet, wenn sich ihr DNA-Gehalt nicht im Bereich 2c $\pm 0,25 \mathrm{c}$ befindet. 2cDI ist definiert als die Summe der Abweichungsquadrate des DNA-Gehaltes der einzelnen Zellen $\left(c_{i}\right)$ vom Mittelwert (2c), geteilt durch die Anzahl der Meßwerte. Der Wert entspricht damit der mittleren quadratischen Abweichung vom Diploid-Wert. Diagnostische Einteilungen maligner Veränderungen können auf den Werten der 5cER und 2cDI bezogen werden.

Als weitere Abstufungsmöglichkeit wurde der Malignitätsindex (MI) als Produkt aus 2cDI und 5cER berechnet. Beide Größen, 2cDI und 5cER, korrelieren eng miteinander (z.B. $r=0,93$ beim malignen Lymphom). Dieser Malignitätsindex wird als quadratische Größe durch eine logarithmische Transformation in den Malignitätsgrad (MG) mit einer Skala von 0,0 bis 3,0 umgewandelt. Damit kann das gesamte Spektrum der Malignität von Tumoren in einem übersichtlichen Score dargestellt werden. Der Algorithmus ist nicht anwendbar für Einflüsse, die eine Aneuploidie simulieren: Bestrahlung oder Zytostatikabehandlung, Läsionen mit Riesenzellproliferation, Amitosen oder euploid polyploidisierte Zellen, wie z.B. Urothelzellen [7]. Entsprechende Patienten wurden nicht in die Studie aufgenommen. 


\section{Zytometrische Klassifikation}

Wir teilten die zytometrischen Befunde in die vier Kategorien 0, I, II oder III ein. Darin bedeuten: 0 keine ausreichende Anzahl repräsentativer epithelialer Zellen, I normale (unauffällige) Zellkernverteilung, II als leichtgradig suspekt wurden daher solche Proben eingestuft, in denen mehr als 10-15 auffällige Kerne in diesem DNA-Bereich gefunden wurden (> Mittelwert der Kontrollgruppe $+2 \mathrm{~s}$ ) und/oder der 2cDI erhöht war. In den bronchialen Spülflüssigkeiten der 50 Kontrollprobanden fanden sich im Mittel lediglich 2,5 $\pm 3,0$ auffällige Kerne mit einem DNA-Index nahe 2,0 (1,75<DNAIndex $<2,25)$. III hochgradig suspekt, neben erhöhtem $2 \mathrm{cDI}$ eine Vielzahl von abnormen Kernen, einschließlich solcher mit einem DNA-Gehalt von mehr als dem fünffachen des normalen haploiden DNA-Gehaltes (5c) oder DNA-Index > 2,5 und einer erhöhten $5 \mathrm{cER}$. Als repräsentative Kernstruktureigenschaften (Features) stellten wir den Zusammenhang zwischen Zellkerngröße und dem DNA-Gehalt bzw. dem DNA-Index im Ergebnisteil exemplarisch dar.

\section{Pathologie}

Für die pathologisch-histologischen Untersuchungen wurden Zangenbiopsien der auffälligen Areale entnommen und im Institut für Pathologie untersucht. Die Proben wurden sofort nach der Gewinnung in 4\%iger Formalinlösung aufgenommen und noch am gleichen Tag verschickt. Nach Spülung der Proben in Aqua dest. wurden sie nach den üblichen histologischen Verfahren nach Passage in Ethanollösungen in zunehmenden Konzentrationen bis zur 100\% Lösung, dann mehreren Passagen in Xylol, Einbettung in Paraffinblöcke, Mikrotomschnitt, Entparaffinierung mit Xylol, dann in Ethanollösungen abnehmender Stärke bis zum Aqua dest aufgearbeitet. Es folgten abschließende Färbungen mit Hämatoxylin und Eosin sowie mit Giemsa-Lösungen. Für spezielle Fragestellungen wurden auch hier weiterführende immunhistochemische Verfahren angewendet. Die histopathologische Zuordnung des führenden Tumortyps im Biopsiegut erfolgte nach der WHOKlassifikation 1981.

\section{Enddiagnose}

Die endgültige Diagnose als Synthese sämtlicher erhobener Daten (klinische Daten, Röntgenuntersuchungen, Bronchoskopie, Zytologie, Histologie) wurde dem Entlassungsbericht entnommen.

\section{Statistik}

Die Ergebnisse der zytometrischen Untersuchungen wurden hinsichtlich der Sensitivität und Spezifität gegenüber der klinischen Enddiagnose als „Goldstandard“ überprüft [32]. In gleicher Weise wurden die Ergebnisse der Zytologie und Histopathologie gegenüber der Enddiagnose getestet.

\section{Ergebnisse}

\section{Kontrollkollektiv ohne Verdacht auf ein Bronchialkarzinom}

Kontrolluntersuchungen erfolgten an 30 Männern (60\%) und 20 Frauen (40\%), bei denen weder röntgenologisch noch anamnestisch der Verdacht auf einen broncho-pulmonalen
Tumor bestand. Das mittlere Alter war vergleichbar zu der Gruppe mit Verdacht auf eine maligne Neoplasie (Mittelwert: $58,2 \pm 11$ Jahre) mit einer Spannweite von 25 bis 76 Jahren. Unter ihnen waren 28 Raucher bzw. Exraucher mit mehr als 20 Packungsjahren. Sämtliche Proben wurden zytometrisch als unauffällig klassifiziert. Die Enddiagnose lautete in 5 Fällen Asthma bronchiale oder bronchiale Hyperreagibilität, in 2 Fällen Sarkoidose, in einem Fall lag eine Sekretretention vor, 31 Patienten zeigten eine Bronchitis und 11 waren bronchoskopisch gänzlich unauffällig.

Das typische zytometrische Bild einer bronchialen Spülflüssigkeit eines Nicht-Tumorpatienten ist gekennzeichnet durch normale Epithelzellkerne in der Interphase $\left(\mathrm{G}_{0}\right.$-Phase) und den Kernen inflammatorischer Zellen, die zusammen ein schmales exponentielles Verteilungsmuster zeigen, wenn die Kerngröße und der DNA-Gehalt in Bezug gesetzt werden, (Abb.1). Der Zusammenhang konnte mit einer Funktion der allgemeinen Form $\mathrm{y}=\mathrm{a}^{*} \mathrm{e}^{\mathrm{b}}+\mathrm{c}$ beschrieben werden.

Kleinere Kerne (<250 Pixel) stammen von den inflammatorischen Zellen (Lymphozyten, sowie segmentförmige und eosinophile Granulozyten). Epithelzellkerne waren in der Regel größer (>250 Pixel). Das Verteilungshistogramm für ihren DNA-Index entsprach weitgehend einer Normalverteilung mit einem Variationskoeffizienten $<10 \%$. Lediglich 0,5 bis $1,0 \%$ der gesammelten epithelialen Kerne zeigen einen DNA-Index im Bereich 1,25 < DNA-Index $<2,5$ auf.

Alveolarmakrophagen starker Raucher (Kondensat-Makrophagen) wiesen zusätzlich zur der DNA-Färbung der Kerne auch Färbungen lysosomaler Strukturen im Zytoplasma auf und täuschen damit eine Aneuploidie vor. Diese Zellen wurden jedoch vom Classifier identifiziert und in die entsprechende Kategorie eingeordnet (s. Abb. 2).

\section{Patienten mit Verdacht auf einen broncho-pulmonalen Tumor}

\section{Altersverteilung männlicher und weiblicher Patienten}

Die Untersuchungen erfolgten an 100 Männern (70\%) und 42 Frauen (30\%). Das mittlere Alter betrug 65,5 Jahre bei einer Spannweite von 26 bis 85 Jahren. Der Alters-Median lag bei den Männern bei 66 und bei den Frauen bei 61 Jahren (Tab. 2). Die größte Altershäufigkeit befand sich unter den Männern in der Gruppe der 61 -70jährigen (42\%). Unter den Frauen war die Altersverteilung weniger homogen, der Altersgipfel (31\%) lag in der Gruppe der 71-80jährigen. Die 95\%-Grenze der kumulativen Häufigkeiten wurde jeweils in der Altersklasse der 71 -80jährigen überschritten.

\section{Zytometrische Ergebnisse in Abhängigkeit vom führenden histologischen Tumortyp}

In 62 Fällen wurden bronchoskopisch direkte TU-Zeichen festgestellt. In 90\% der Proben zeigten sich auch in der zytometrischen Untersuchung pathologische Befunde im Sinne einer vermehrten Anzahl aneuploider Zellkerne (25 III, 31 II). Nur vier Proben waren unauffällig (I) und zwei enthielten zu wenig Material (0).

Indirekte Tumorzeichen wurden in 31 Fällen gefunden; 84\% davon waren auch zytometrisch auffällig. Bronchoskopisch 

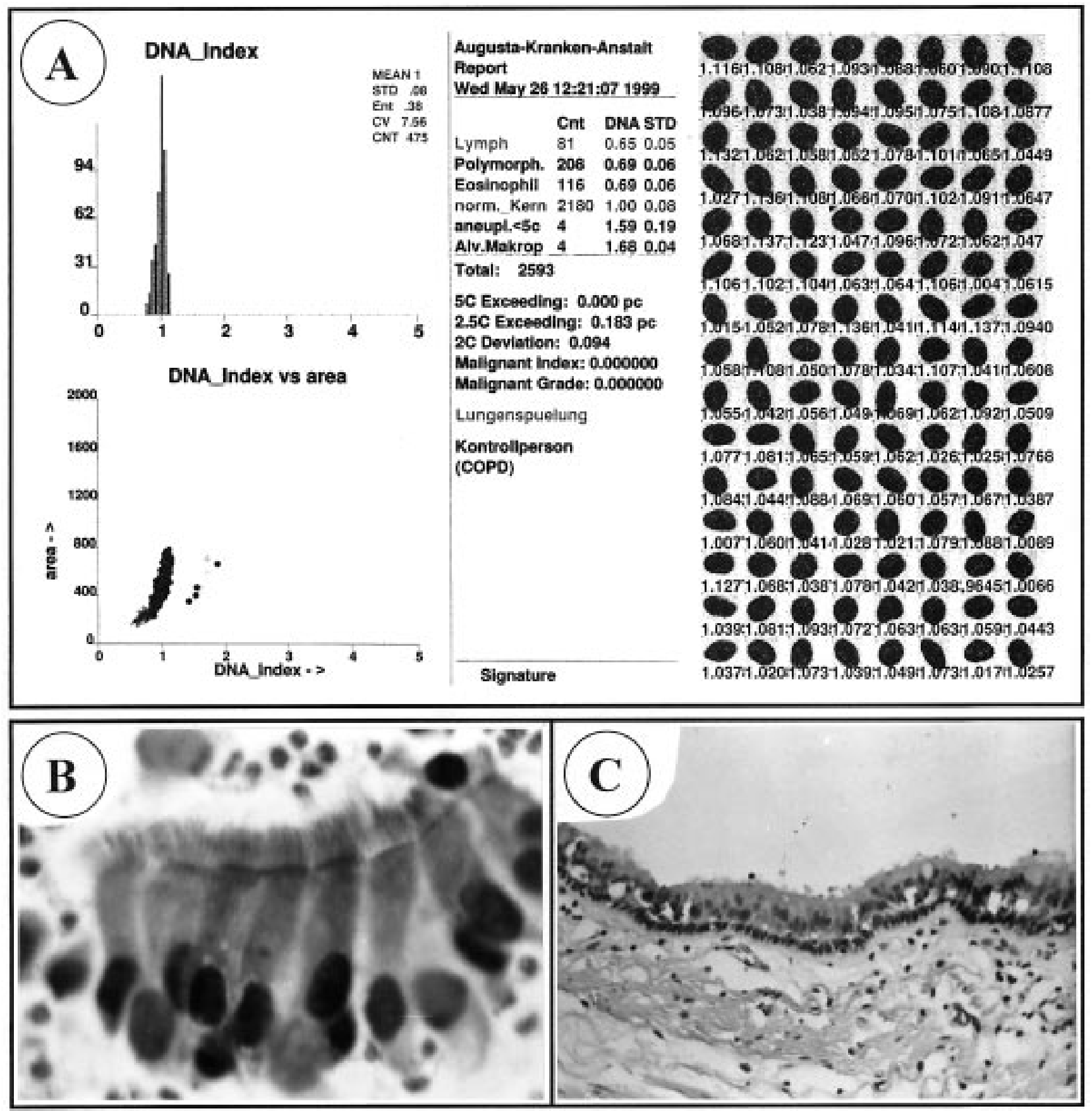

Abb. 1 Beispiel für ein unauffälliges zytometrisches Untersuchungsergebnis von Probenmaterial einer bronchialen Spüllösung von einem Patienten mit COPD, bei dem kein Verdacht auf ein Bronchialkarzinom bestand und im Rahmen der klinischen Diagnostik nicht vorlag. A: zytometrischer Report mit Darstellung der Häufigkeitsverteilung des DNA-Gehaltes, der Beziehung zwischen DNA-Index und Kerngröße, einer tabellarischen Darstellung der Anzahl der gesammelten Zellen der einzelnen Gruppen, die Raten der 2,5c- und 5c überschreitenden Kerne (2,5c Exceeding und 5c Exceeding) sowie dem Malignitätsindex und Malignitätsgrad und schließlich einer Galerie typischer unauffälliger Epithelzellkerne. B: zytologische Darstellung von Flimmerepithelzellen und C: histologische Abbildung der Bronchialschleimhaut.

konnten bei 49 Patienten (davon 16 mit röntgenologisch gesichertem peripheren Rundherd) keine tumorverdächtigen Veränderungen festgestellt werden. Jedoch fanden wir in $56 \%$ der Patienten mit peripherem Rundherd auffällige zytometrische Ergebnisse. Unter den bronchoskopisch unauffälligen Patienten, bei denen röntgenologisch kein peripherer Rund- herd nachgewiesen wurde, fanden wir in 9 Proben (18\%) ein positives zytometrisches Untersuchungsergebnis (6 II).

Insgesamt fanden wir in 43 Fällen einen hochgradig suspekten Befund mit einer Vielzahl von auffälligen Zellkernen (III). 54 Präparate waren leichtgradig suspekt mit einigen abnormalen Zellen (II), 36 waren unauffällig (I) und in 9 
Tab. 1 Bronchoskopische Tumoridentifikation und zytometrische Befundung mit dem Cyto-Savant ${ }^{\circledR}$

\begin{tabular}{|c|c|c|c|c|c|c|c|}
\hline \multirow[t]{2}{*}{ Bronchoskopisches Bild } & \multirow[t]{2}{*}{ Anzahl } & \multirow[t]{2}{*}{ \% der Fälle } & \multirow[t]{2}{*}{ pos. Rate } & \multicolumn{4}{|c|}{ zytometrische Klassifikation } \\
\hline & & & & III & II & & 0 \\
\hline direkte Tumorzeichen & 62 & 44 & 90 & 25 & 31 & 4 & 2 \\
\hline indirekte Tumorzeichen & 31 & 22 & 84 & 14 & 12 & 2 & 3 \\
\hline pRH, bronchoskopisch ohne Tumorbefund & 16 & 11 & 56 & 4 & 5 & 6 & 1 \\
\hline kein pRH, bronchoskopisch ohne Tumorbefund & 33 & 23 & 18 & 0 & 6 & 23 & 3 \\
\hline Summe & 142 & & & 43 & 54 & 36 & 9 \\
\hline
\end{tabular}

III: hochgradig suspekt mit zahlreichen auffälligen Kernen, einschließlich 5cER > 1\%, II: leichtgradig suspekt mit einzelnen auffälligen Kernen, I: unauffällig, 0: nicht repräsentativ, keine ausreichende Anzahl repräsentativer Kerne, pRH: peripherer Rundherd.

Tab. 2 Tumorklassifikation und zytometrische Diagnose bronchialer Spülflüssigkeiten mit dem Cyto-Savant ${ }^{\circledR}$

\begin{tabular}{|c|c|c|c|c|c|c|c|c|}
\hline \multirow[t]{2}{*}{ abschließende Diagnose } & \multirow[t]{2}{*}{ Anzahl } & \multirow[t]{2}{*}{ \% der Fälle } & \multirow[t]{2}{*}{$\%$ der TU } & \multirow[t]{2}{*}{ pos. Rate } & \multicolumn{4}{|c|}{ zytometrische Klassifikation } \\
\hline & & & & & III & II & & 0 \\
\hline Entzündungsreaktionen & 34 & 24 & & & 0 & 5 & 26 & 3 \\
\hline kleinzellige Karzinome & 28 & 20 & 26 & 100 & 17 & 8 & 0 & 3 \\
\hline Plattenepithelkarzinome & 25 & 18 & 23 & 96 & 6 & 17 & 1 & 1 \\
\hline großzellige Karzinome & 9 & 6 & 8 & 88 & 4 & 4 & 1 & 0 \\
\hline Adenokarzinome & 37 & 26 & 34 & 86 & 15 & 15 & 5 & 2 \\
\hline Metastasen/div. Tumoren & 9 & 6 & 8 & 66 & 1 & 5 & 3 & \\
\hline Summe & 142 & 100 & & & 43 & 54 & 36 & 9 \\
\hline
\end{tabular}

III: hochgradig suspekt mit zahlreichen auffälligen Kernen, einschließlich 5cER > 1\%, II: leichtgradig suspekt mit einzelnen auffälligen Kernen, I: unauffällig, 0: nicht repräsentativ, keine ausreichende Anzahl repräsentativer Kerne.

Tab. 3 Sensitivität und Spezifität der quantitativen Image-Zytometrie bronchialer Spülflüssigkeiten in der Diagnose des Lungenkrebses

\begin{tabular}{lllllllc}
\hline Methode & Anzahl & Sensitivität \% & Spezifität \% & korrekt-positiv & falsch-positiv & falsch-negativ & korrekt-negativ \\
\hline Zytometrie & 133 & 90 & 84 & 92 & 5 & 10 & 26 \\
Zytologie & 126 & 92 & 100 & 92 & 0 & 8 & 26 \\
Pathologie & 86 & 91 & 100 & 73 & 0 & 7 & 6 \\
\hline
\end{tabular}

Proben befand sich zu wenig repräsentatives Material für die Befundung (0) (Tab.1).

Zytometrische Befundung im Vergleich zur histogenetischen Tumorklassifikation

Der Verdacht auf das Vorliegen eines broncho-pulmonalen Tumors konnte histologisch oder zytologisch bei 108 der 142 untersuchten Patienten in der Enddiagnose gesichert werden (Tab. 2). Unter den Tumoren waren kleinzellige Karzinome in $26 \%$ der Tumorfälle vertreten, die davon untersuchten Präparate waren alle zytometrisch auffällig. Unter den nicht-kleinzelligen Tumoren waren Plattenepithelkarzinome mit 23\%, Adenokarzinome mit 34\% und großzellige Karzinome in $8 \%$ vertreten.

\section{Enddiagnose als „Goldstandard“}

Der Vergleich mit der abschließenden Enddiagnose aus sämtlichen Untersuchungsergebnissen als „Goldstandard“, zeigte eine zur Zytologie mit 92\% und Histopathologie mit 91\% vergleichbare Sensitivität der Zytometrie von $90 \%$ (Tab. 3).

Bei einem Vergleich der Spezifität, die bei den konventionellen mikroskopischen Verfahren bei $100 \%$ lag, führten fünf falsch-positive Befunde in der Image-Zytometrie bisher zu einer Spezifität von 84\%. Für die Zytometrie erhielten wir einen positiven Vorhersagewert von $95 \%$ und einen negativen Vorhersagewert von $71 \%$.

Beispiele zytometrischer Untersuchungsergebnisse

Normalbefund: Ein unauffälliges zytometrisches Untersuchungsergebnis der bronchialen Spülflüssigkeiten von einem nicht-rauchenden Patienten mit einer chronisch obstruktiven Lungenerkrankung (COPD) zeigt einen exponentiellen Zusammenhang zwischen Zellkerngröße (Area) und DNA-Gehalt (DNA-Index) ( Abb.1). Die rundlichen bis ovalen epithelialen Kerne zeigen ein feinkörniges Chromatinverteilungsmuster. Es finden sich zarte Chromozentren und eine ausgeglichene 

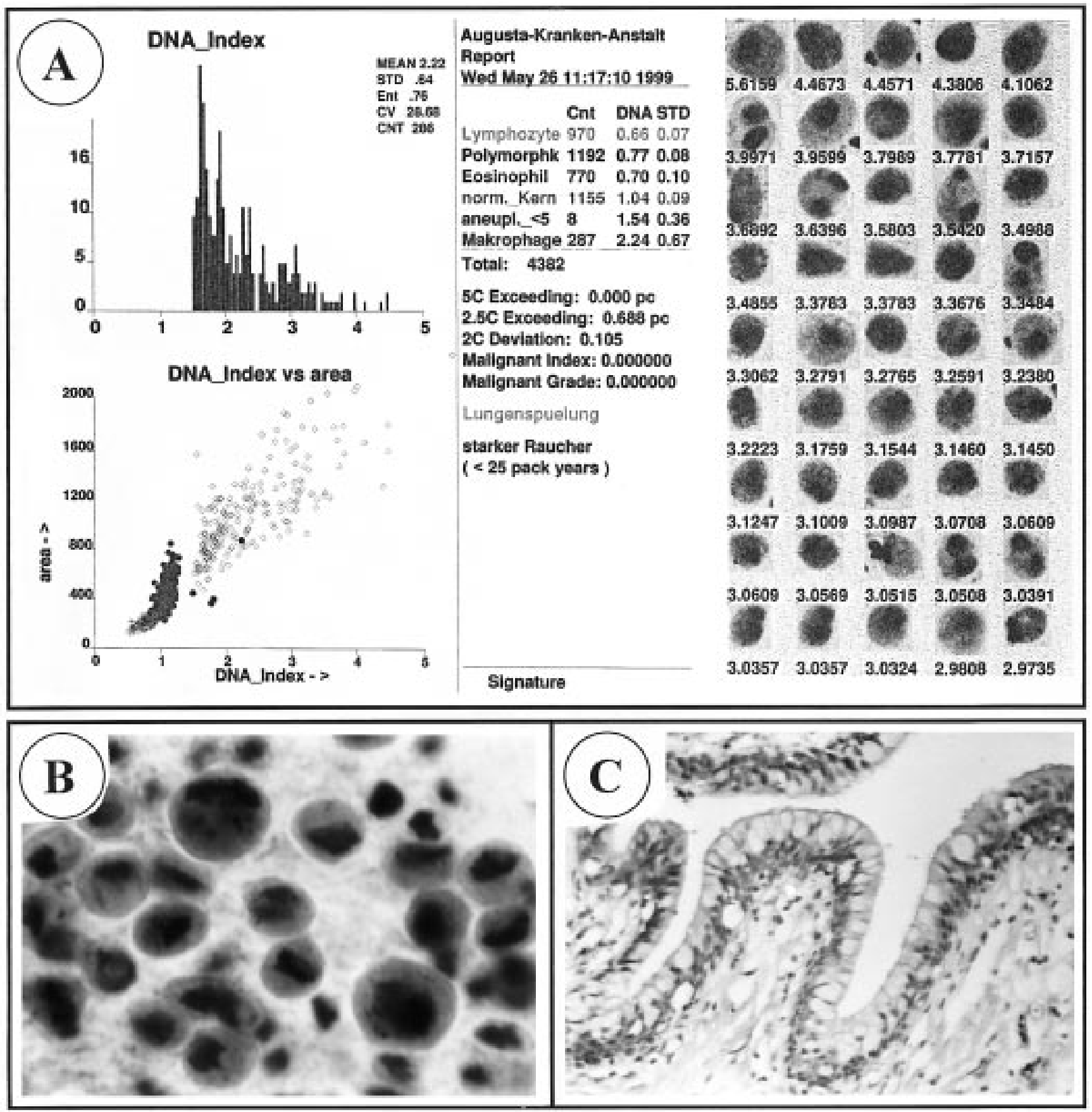

Abb. 2 Beispiel für ein zytometrisches Untersuchungsergebnis von Probenmaterial einer bronchialen Spüllösung eines starken Rauchers, bei dem der Verdacht auf ein Bronchialkarzinom im Rahmen der klinischen Diagnostik nicht bestätigt werden konnte. A: zytometrischer Report mit Darstellung einer Galerie typischer Kondensatalveolarmakrophagen bei Kondensatpneumopathien, die eine Aneuploidie vortäuschen. B: zytologische Darstellung der Kondensatalveolarmakrophagen und C: histologische Abbildung der Bronchialschleimhaut.

Verteilung des Eu- und Heterochromatins. Sie weisen einen DNA-Index von 0,75 bis 1,25 auf und befinden sich im Bereich einer Kerngröße von 250-800 Pixeln. Nur einzelne Kerne haben einen DNA-Index um 2,0, dabei handelt es sich vermutlich um Zellen in der G2-Phase der mitotischen Teilung.

Proben von Rauchern: Typisch für die Kernverteilung eines starken Rauchers (Abb. 2) sind, neben dem üblichen Verteilungsmuster der normalen Epithelzellkerne auch eine Viel- zahl von teils polyploiden Kondensatalveolarmakrophagen, bei denen sich zusätzlich Zytoplasmaeinschlüsse darstellen. Da diese Einschlüsse ebenfalls photometrisch erfaßt werden, werden die Zellen als aneuploid klassifiziert. Der Classifier erkennt diese Zellen jedoch und ordnet sie in die entsprechende Gruppe der Kondensatalveolarmakrophagen ein. Die Größe dieser Zellen ist sehr unregelmäßig (3003000 Pixel) und der scheinbare DNA-Gehalt häufig größer $5 c(5 \mathrm{c}$ ER $>5 \%)$. 

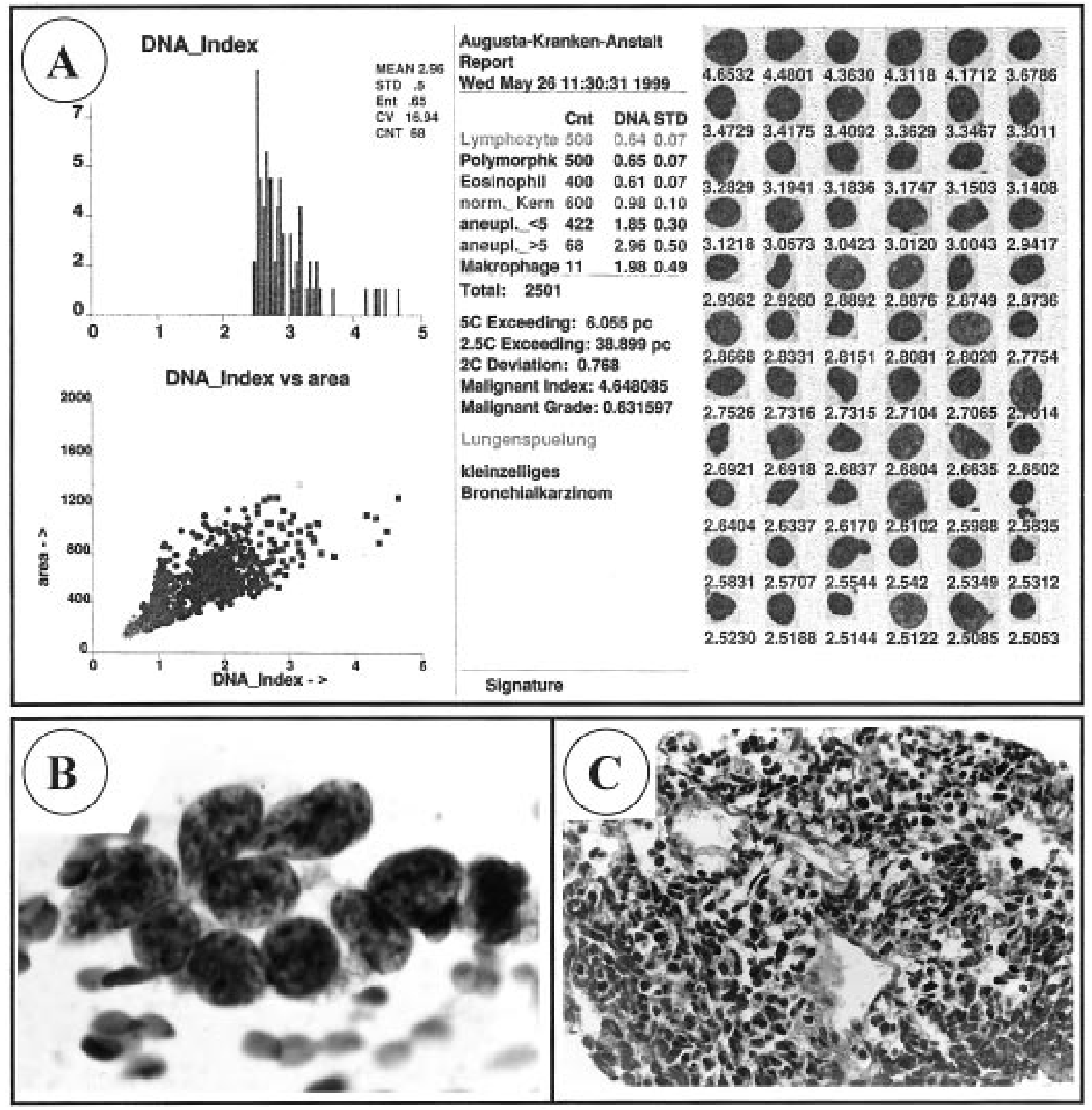

Abb. 3 Beispiel für ein pathologisches zytometrisches Untersuchungsergebnis von Probenmaterial einer bronchialen Spüllösung eines Patienten mit kleinzelligem Bronchialkarzinom im fortgeschrittenen Stadium. A: zytometrischer Report mit Darstellung einer Galerie typischer aneuploider Tumorkerne, B: zytologische und C: histologische Darstellung des kleinzelligen Bronchialkarzinoms.

Kleinzellige Bronchialkarzinome: In der Spülflüssigkeit der Patienten mit kleinzelligen Bronchialkarzinomen im fortgeschrittenen Stadium (Abb. 3) sind neben dem üblichen Verteilungsmuster normaler Kerne eine Vielzahl intensiv angefärbter aneuploider Kerne einschließlich solcher mit einem DNAGehalt größer $5 c$ ( $5 c$ ER $>1 \%)$ jedoch mit wenig veränderter Kerngröße (300-800 Pixel) und einem mittleren DNA-Index von $1,83 \pm 0,74$ vorhanden. Das Chromatinmuster ist grobkörnig bis grobfaserig und weist häufig große Chromozentren auf. Die Kernränder sind unregelmäßig. Die Kerne sind polygonal, teils rundlich-oval bis tropfenförmig.

Plattenepithelkarzinome: In der bronchialen Spülflüssigkeit von Patienten mit Plattenepithelkarzinomen (Abb.4) finden sich neben dem üblichen Verteilungsmuster der normalen epithelialen Kerne, regelmäßig eine Vielzahl von auffälligen und vergrößerten aneuploiden Zellkernen mit einer Fläche bis zu 2000 Pixeln. Die Kerne sind rundlich bis oval und glatt- 

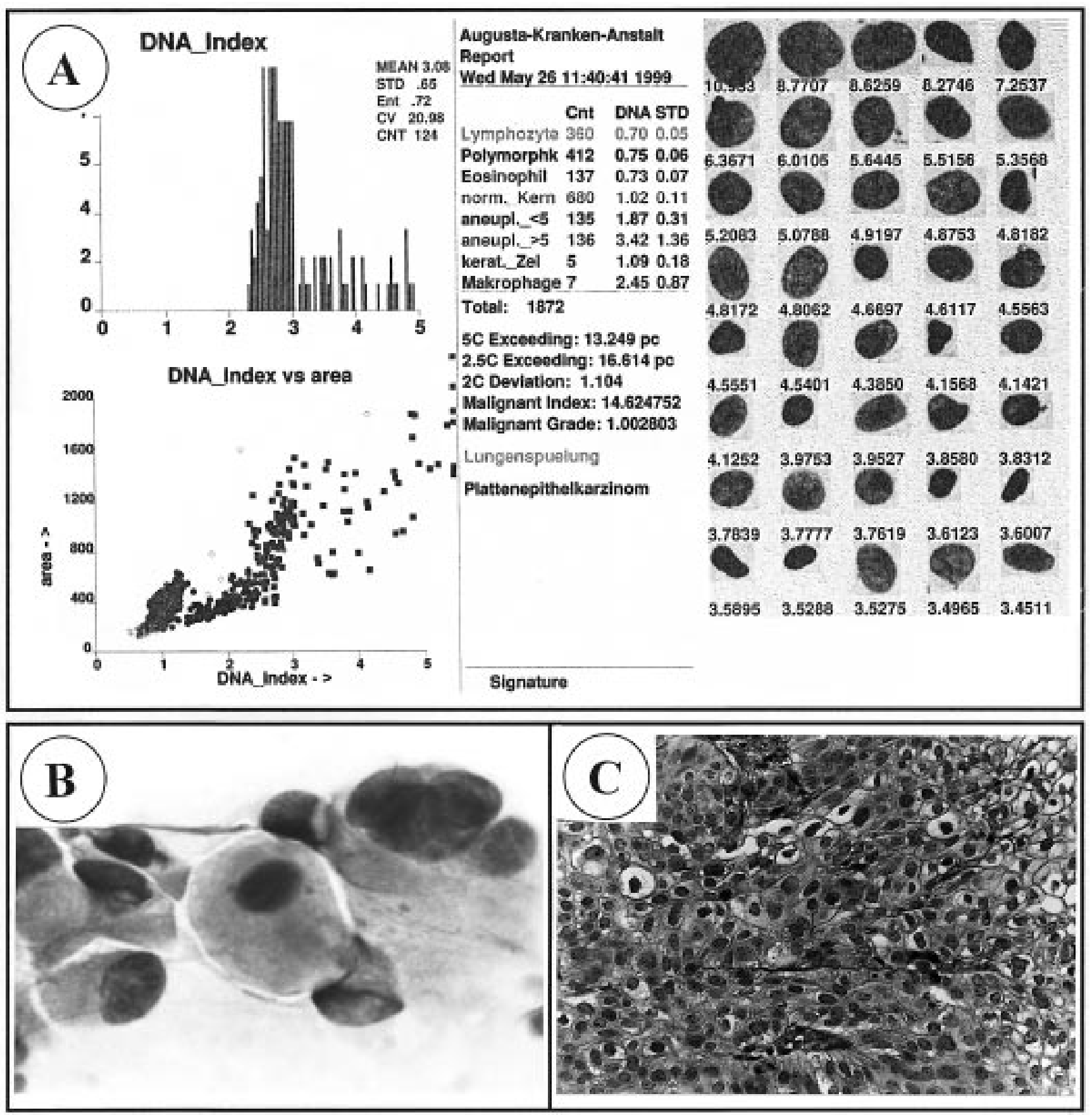

Abb. 4 Beispiel für ein pathologisches zytometrisches Untersuchungsergebnis von Probenmaterial einer bronchialen Spüllösung eines Patienten mit einem Plattenepithelkarzinom. A: zytometrischer Report mit Darstellung einer Galerie typischer aneuploider Tumorkerne, B: zytologische und C: histologische Darstellung des Plattenepithelkarzinoms.

randig. Das Chromatinmuster ist grobkörnig mit großen Chromozentren, gelegentlich finden sich auch pyknotische Kerne mit sehr hohem DNA-Index.

Adenokarzinome: In der bronchialen Spülflüssigkeit von Patienten mit Adenokarzinomen (Abb.5) finden sich typischerweise auffällige Zellen mit aneuploiden Kernen einschließlich solcher mit einem DNA-Gehalt größer $5 c$ (5c
ER $>0,5 \%$, die weniger hinsichtlich ihrer Kerngröße als vielmehr in ihrem DNA-Gehalt von normalen Epithelzellkernen abweichen. Die Kerne sind häufig halbmondförmig, besitzen einen vermehrten Heterochromatinanteil. Gelegentlich finden sich eine helle Kernmatrix und gelappte bzw. polyploide Kerne. 

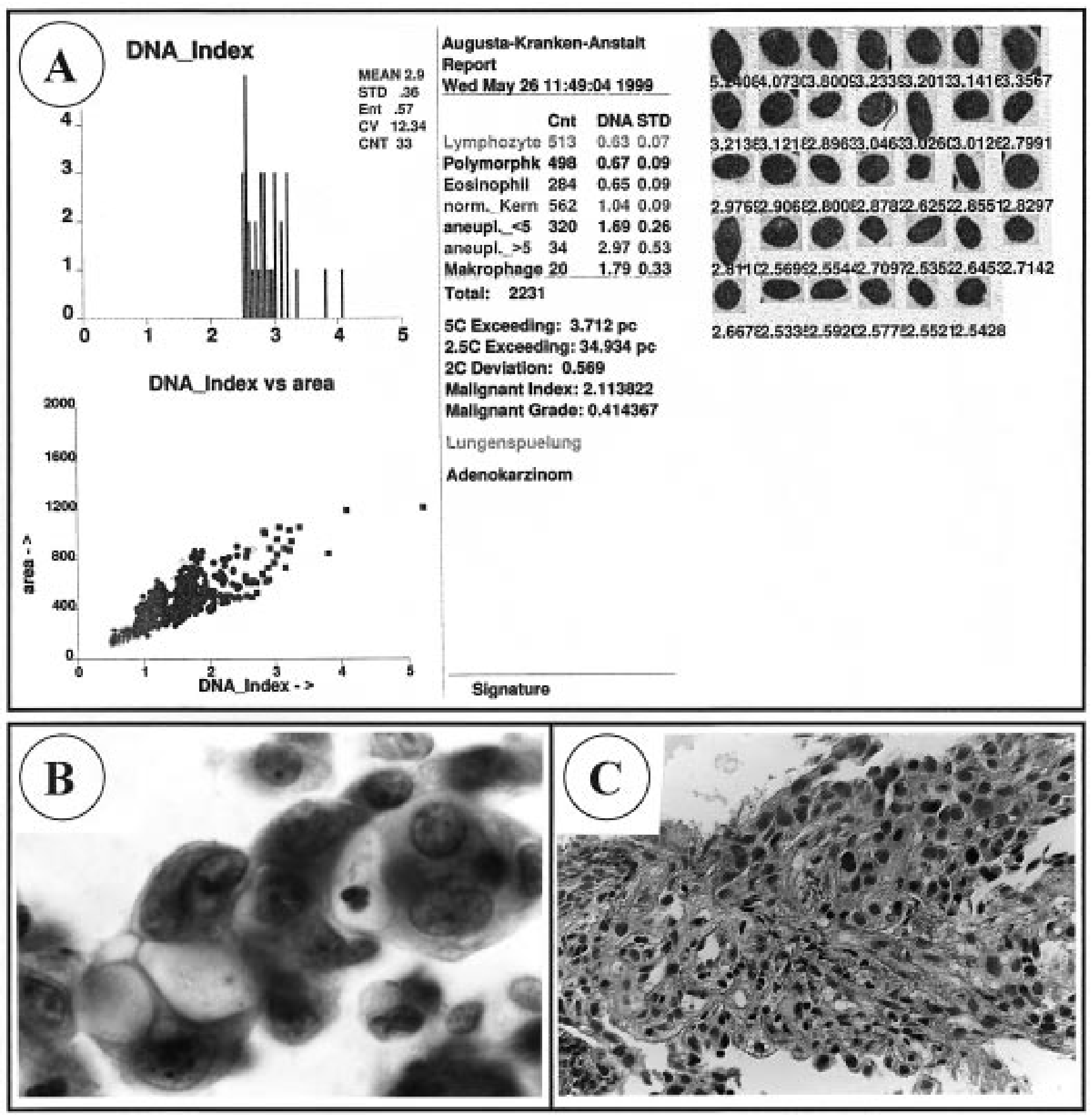

Abb. 5 Beispiel für ein pathologisches zytometrisches Untersuchungsergebnis von Probenmaterial einer bronchialen Spüllösung von einem Patienten mit einem Adenokarzinom. A: zytometrischer Report mit Darstellung einer Galerie typischer aneuploider Tumorkerne, B: zytologische und C: histologische Darstellung des Adenokarzinoms.

\section{Diskussion}

Die quantitative automatisierte Image-Zytometrie bronchialer Spülflüssigkeiten zeigte in unserer Untersuchung im Vergleich zur Enddiagnose eines broncho-pulmonalen Tumors als „Goldstandard“ eine Sensitivität von $90 \%$, die mit der bei der Untersuchung zytologischer und histologischer Biopsien ermittelten Sensitivität vergleichbar war. Die Spezifität jedoch lag mit 84\% noch unter der der konventionellen mikroskopischen Verfahren (100\%).

Vergleich $z u$ früheren Untersuchungen: Im Vergleich mit anderen Studien zur Evaluation bronchialer Spülflüssigkeiten bei der Diagnose broncho-pulmonaler Tumoren zeigten unsere mit dem automatisierten Zytometer erzielten Ergebnisse eine weitaus höhere Sensitivität. So gaben Gracia et al. [10] 
eine Sensitivität von nur 33\% für die Auswertung bronchialer Spüllösungen allein und 56\% für die Kombination der Untersuchung bronchialer Spüllösung mit broncho-alveolärer Lavage und postbronchoskopischem Sputum an. Pirozynski [30] kam in einer vergleichbaren Studie auf eine Sensitivität von $64 \%$.

Verschiedene Autoren beschrieben eine Abhängigkeit der Sensitivität zytologisch untersuchter bronchialer Spülflüssigkeiten von der Tumorlokalisation und Größe $[25,30]$. Bei den hier untersuchten 142 Patienten ergab die Bronchoskopie in $22 \%$ ein vorwiegend submuköses Tumorwachstum, in $44 \%$ konnte ein exophytisch wachsender Tumor im einsehbaren Bereich identifiziert werden, in $11 \%$ war der röntgenologisch nachweisbare periphere Rundherd bronchoskopisch nicht darstellbar. Wir fanden eine höhere positive Identifikationsrate in solchen Fällen, in denen der Tumor direkt bronchoskopisch gesichtet werden konnte ( $84 \%$ bei submukösem Tumorwachstum, $90 \%$ bei exophytischem Tumorwachstum). In den Fällen, bei denen bronchoskopisch ein unauffälliger Befund erhoben wurde, fanden wir bei Patienten mit radiologisch gesichertem peripheren Rundherd, in mehr als der Hälfte (56\%) der Proben zytometrisch auffällige Kerne. Dies unterstreicht die Bedeutung der Untersuchung von Untersuchungsgut bronchialer Spülflüssigkeiten bei peripheren Lungentumoren.

Bei den oben erwähnten Untersuchungen bronchialer Spülflüssigkeiten mittels herkömmlicher zytologischer Methoden gaben die Autoren eine Spezifität von $100 \%$ an, die durch die hier durchgeführte quantitative Image-Zytometrie mit ihrer Spezifität von $84 \%$ nicht erreicht wurde. Verantwortlich sind „5 falsch-positive“ Ergebnisse bei 34 Patienten, bei denen zum Zeitpunkt der Untersuchung kein Tumor festgestellt werden konnte. Die Proben dieser Patienten, die ausnahmslos eine entzündliche Atemwegserkrankung aufwiesen, enthielten allerdings nur einzelne auffällige Kerne mit einem DNAIndex nahe 2,0. Auf entzündungsbedingte Kernveränderungen wurde in der Literatur bereits hingewiesen [8]. Diese Patienten sind für ein Follow-up vorgesehen.

Sensitivität bei der Erfassung unterschiedlicher Tumortypen und Lokalisationen: Ein weiterer Aspekt, den wir bei unseren Untersuchungen näher beleuchten wollten, war die Frage nach einer Abhängigkeit der image-zytometrischen Untersuchungen von der histologischen Tumorklassifikation. Dabei unterschieden wir nach den führenden histologischen Tumortypen Plattenepithelkarzinome, Adenokarzinome, kleinzellige sowie großzellige bzw. heterogen differenzierte Karzinome und faßten andere seltenere Tumoren und Metastasen anderer Primärtumoren in einer Gruppe zusammen [21].

Im Unterschied zur Untersuchung von Pirozynski [25], der eine besonders hohe positive Rate bei den Adenokarzinomen und eine relativ geringe Spezifität für Plattenepithelkarzinome beschrieb, fanden wir die höchste positive Rate bei den kleinzelligen Karzinomen mit 100\% aller verwertbaren Proben. Aber auch für das Plattenepithelkarzinom fanden wir noch eine positive Rate von $96 \%$. Die geringste positive Rate enthielt bei unseren Untersuchungen die Gruppe der selteneren Karzinome und Metastasen anderer Primärtumoren mit 66\%. Einen eindeutigen Qualitätsunterschied bei der zytometrischen Diagnose konnten wir hieraus nicht ableiten, wir konnten lediglich feststellen, daß kleinzellige Bronchialkarzinome sowie Plattenepithelkarzinome in der Zytometrie geringfügig besser darzustellen waren als Adenokarzinome und nach histologischen Kriterien kombinierte Karzinome. Die besonders hohe Ausbeute unter den kleinzelligen Tumoren wies auf fortgeschrittene Stadien dieser Erkrankung in der von uns untersuchten Population hin.

Man könnte den Unterschied bei den Plattenepithelkarzinomen auch auf eine zentralere Lokalisation zurückführen, an der gezielter gespült werden konnte. Es könnte sich hierbei aber auch um relevante Unterschiede in der Tumorprogredienz zum Zeitpunkt der Untersuchung handeln. Weitere Untersuchungen an größeren Patientenkollektiven finden z.Z. statt. Dabei werden die typischen Feature-Konstellationen für die unterschiedlichen Tumorarten mit dem Ziel zusammengestellt, ein Trainingsset aus typischen Kernen der einzelnen Tumoren für den Cell-classifier zusammenzustellen. Im Rahmen dieses Vorgehens ist zu berücksichtigen, daß verschiedene Autoren angeben, daß ein bedeutender Anteil der malignen Tumoren histologisch variabel kombinierte Zellbilder enthalten $[15,22]$. Warum diese Untersuchung auch im Vergleich mit der von Pirozynski nicht ähnliche Resultate hervorbrachte, bleibt noch offen und zeigt, daß sicherlich auch das Tumorstaging in weiterführenden Untersuchungen berücksichtigt werden muß.

Zusammenfassung: Wir können feststellen, daß sich die quantitative Image-Zytometrie bronchialer Spülflüssigkeiten zunehmend als eine empfindliche Methode zur Auffindung von malignen Veränderungen im Atemtrakt erweist. Im Vergleich mit anderen Methoden liegt ihre herausragende Bedeutung sicherlich im Bereich der peripheren, bronchoskopisch nur schlecht zu erreichenden Lungentumoren. Hier kann sie erste diagnostische Hinweise für das Bestehen eines bronchopulmonalen Tumors liefern. Bei den zentral lokalisierten Neoplasien kann die automatisierte Image-Zytometrie unterstützend zu anderen Diagnoseverfahren eingesetzt werden. Besonders bei Risikopatienten mit Blutungsneigung z. B. unter Marcumar stellt sie eine wenig invasive und dennoch hoch sensitive Methode zur Probengewinnung dar.

Da die Probenaufarbeitung und -auswertung durch ihre weitgehende Automatisierung zeitsparend für das Labor sind, könnte der Einsatz der automatisierten Image-Zytometrie in Zukunft sicherlich auch für ein Screening von Hochrisikopatienten, wie z.B. radon- oder asbestexponierten Arbeitnehmern oder langjährigen Rauchern sinnvoll sein. Dabei kann die Probeentnahme nicht nur im Rahmen einer Bronchoskopie erfolgen, sondern auch mittels Sputuminduktion in einer Arztpraxis erfolgen. Eine Probengewinnung kann aber auch - nach entsprechender Unterweisung - zu Hause beim Patienten erfolgen, sofern dieser spontan genug Sputum abhustet und eine Sammlung über drei Tage durchführt.

Fazit für die Klinik und Praxis: Diese Arbeit verifiziert die hohe Sensitivität und Spezifität der automatisierten Image-Zytometrie bronchialer Spülflüssigkeiten im Vergleich zu den Standardverfahren der Zyto- und Histopathologie. Die weitgehende Automatisierung begünstigt ihren Einsatz bei größeren Patientenkollektiven. 


\section{Literatur}

${ }^{1}$ American Cancer Society. In: Cancer Facts \& Figures. American Cancer Society. Atlanta: 1995

${ }^{2}$ Atay Z, Topalidis T. Neoplasien. In: Cytodiagnostik der serösen Höhlen. edited by Z. Atay and T. Topalidis. Lengerich, Berlin: Pabst Verlag; 1994. p. 89 - 214

${ }^{3}$ Auffermann W, Böcking A. Early Detection of precancerous lesions in dysplasias of the lung by rapid DNA image cytometry. Anal Quant Cytol Histol 1985; 7: 218 - 226

${ }^{4}$ Auffermann W, Repges R, Böcking A. Rapid diagnostic DNACytometry with an automatic microscope and a TV imageanalysis system. Analytical and Quantitative Cytology 1984; 6: $179-188$

${ }^{5}$ Bang KM, White JE, Gause BL. Evaluation of recent trends in cancer mortality in incidence among blacks. Cancer 1988; 61: $1255-1261$

${ }^{6}$ Böcking A. Abklärung plattenepithelialer Dysplasien mittels DNA-Bildzytometrie. Deutsches Ärzteblatt 1998; 95: A-658 - A662

${ }^{7}$ Böcking A, Adler CP, Common HH, Hilgarth M, Granzen B, Auffermann W. Algorithm for a DNA-Cytophotometric Diagnosis and Grading of Malignancy. Analytical and Quantitative Cytology 1984; 6: $1-8$

${ }^{8}$ Böcking A, Biesterfeld R, Chatelain R, Gien-Gerlach G, Esser E. Diagnosis of bronchial carcinoma on sections of paraffin-embedded sputum: sensitivity and specificity of an alternative to routine cytology. Acta Cytol 1992; 36: 37 - 47

${ }^{9}$ Böcking A, Giroud F, Reith A. Consensus report of the ESACP task force on standardization of diagnostic image cytometry. Anal Cell Pathol 1995; 8: $67-74$

10 deGarcia J, Bravo C, Miravitlles M, Tallada N, Orriols R, Bellmunt J, Vendrell M, Morell F. Diagnostic value of bronchoalveolar lavage in peripheral lung cancer. Am Rev Respir Dis 1993; 147: $649-652$

${ }^{11}$ Doudkine A, MacAulay C, Poulin N, Palcic B. Nuclear texture measurements in image cytometry. Pathologica 1995; 87: 286 299

12 Ernster VL, Mustacchi P, Osann KE. Epidemiology of lung cancer. J Neoplasms of the lungs 1992; 47: $1504-1527$

${ }^{13}$ Feulgen R, Rossenbeck H. Mikroskopisch-chemischer Nachweis einer Nukleinsäure vom Typus der Thymonukleinsäure und die darauf beruhende selektive Färbung von Zellkernen in mikroskopischen Präparaten. Z Physiol Chemie 1924; 135: 203 - 248

${ }^{14}$ Garner D, Harrison A, MacAulay C, Palcic B. Cyto-Savant (TM) and its use in automated screening of cervical smears. In: Compendium on the Computerized Cytology and Histology Laboratory. edited by G. L. Wied, P. H. Bartels, D. L. Rosenthal and U. Schenck. Chicago, Ill: Tutorials of Cytology; 1994. p. $346-352$

${ }^{15}$ Höring E, Wörmann B, Büchner T, Müller KM. Heterogeneity of tumor cells in human bronchial carcinoma. Histological and flow-cytometrical analysis. In: Verh Dtsch Krebs Ges. edited by A Georgii. Stuttgart: Fischer; 1982. p. 846

${ }^{16}$ Ihde DC, Minna JD. Non-small cell lung cancer. Part I. Biology, diagnosis, and staging. Curr Probl Cancer 1991; 15: 61 - 104

${ }^{17}$ Jacobson DR, Fishman CL, Mills NE. Molecular genetic tumor markers in the early diagnosis and screening of non-small-cell lung cancer. Ann Oncol 1995; 6, Suppl 3: $3-8$

${ }^{18}$ Lam S, MacAulay C, Palcic B. Detection and localization of early lung cancer by imaging techniques. Chest 1993; 103: $12-14$

${ }^{19}$ Marek W, Köhler C, Nielsen L, Khanavkar B, Muti A, Nakhosteen JA. Ermittlung eines Normalkollektivs für die automatisierte Sputumzytometrie (ASC). Atemw-Lungenkrkh 1998; 24: 320 323
${ }^{20}$ Motherby H, Marcy T, Hecker M, Ross B, Nadjari B, Auer H, Müller KM, Häussinger D, Strauer BE, Böcking A. Static DNA Cytometry as a diagnostic aid in effusion cytology. I. DNA aneuploidy for identification and differentiation of primary and secondary tumors of the serous membranes. Anal Quant Cytol Histol 1998; 20: 153 - 161

${ }^{21}$ Müller KM. Morphologische Diagnostik. In: Atlas und Lehrbuch der thorakalen Endoskopie. Bronchoskopie und Thorakoskopie. edited by J. A. Nakhosteen and R. Inderbitzi. Berlin, Heidelberg, New York: Springer; 1994. p. $101-128$

${ }^{22}$ Müller KM, Brämer UG, Hiddemann W. Probleme der morphologischen Klassifikation bösartiger Lungentumoren. Atemw-Lungenkrkh 1986; 12: 459 - 465

${ }^{23}$ Müller KM, Hirschberg M. Alveolar macrophages after chronic tabacco smoke inhalation and after artificial respiratory therapy for acute pulmonary failure. Klinische Wochenschrift 1984; 66: $43-50$

${ }^{24}$ Nakhosteen JA, Khanavkar B, Muti A, Marek W. Früherkennung des Bronchialkarzinoms durch Autofluoreszenz(LIFE)-Bronchoskopie und automatisierte Sputumzytometrie. Die nächste Generation. Atemw-Lungenkrkh 1997; 23: 211 - 217

${ }^{25} \mathrm{Ng}$ ABP, Horak GC. Factors significant in the diagnostic accurancy of lung cytology in bronchial washing and sputum samples: II. Sputum samples. Acta Cytol 1983; 27: 397 - 402

${ }^{26}$ Nielsen L, Marek W, Khanavkar B, Muti A, Nakhosteen JA. Optimierung der Probenaufbereitung für die automatisierte Sputumzytometrie (ASC) mittels Dithiotreitol (DTT). AtemwLungenkrkh 1998; 24: $324-326$

${ }^{27}$ Papanicolaou GN. A new procedure for staining vaginal smears. Science 1942; 95: 438 - 439

${ }^{28}$ Papanicolaou GN, Bridges EL. Simple method for protecting fresh smears from drying and deterioration during mailing. JAMA 1957; $164: 1330$ - 1331

${ }^{29}$ Payne PW, Sebo TJ, Doudkine A, Garner D, MacAulay C, Lam S, LeRiche JC, Palcic B. Sputum screening by quantitative microscopy: A reexamination of a portion of the National Cancer Institute Cooperative Early Lung Cancer Study. Mayo Clin Proc 1997; 72: 697 - 704

${ }^{30}$ Pirozynski M. Bronchoalveolar lavage in the diagnosis of peripheral, primary lung cancer. Chest 1992; 102: 372 - 374

${ }^{31}$ Saccomanno G, Archer VE, Auerbach O, Saunders RP, Brennan LM. Development of carcinoma of the lung as reflected in exfoliated cells. Cancer 1974; 33: 256 - 270

${ }^{32}$ Sachs L. Angewandte Statistik. Anwendung statistischer Methoden. edited by L. Sachs. Berlin, Heidelberg, New York: Springer Verlag; 1992. p. $1-864$

${ }^{33}$ Schulte E. Air drying as a preparatory factor in cytology: investigation of its influence on dye uptake and dye binding. Diagn Cytopathol 1986; 2: 160 - 167

${ }^{34}$ Schulte E. Standardization of the Feulgen reaction for absorption DNA image cytometry: a review. Anal Cell Pathol 1990; 2: 149 157

${ }^{35}$ Schulte E, Wittekind DH. Standardization of the Feulgen-Schiff technique: staining characteristics of pur fuchsin dyes, a cytophotometric investigation. Histochemistry 1989; 91: 321 - 331

\section{Priv.-Doz. Dr. rer. nat. Wolfgang Marek}

Forschungsinstitut für Frühdiagnose und Therapie des Bronchialkarzinoms

Klinik für Pneumologie und respiratorische Allergologie Augusta-Kranken-Anstalt

Bergstr. 26

44791 Bochum

E-mail: Wolfgang.Marek@ruhr-univ-bochum.de 